\title{
Effect of Nanosilica on the Mechanical Properties and AC Electrical Breakdown Strength of Epoxy/Microsilica/ Nanosilica Composite
}

\author{
Jae-Jun Park \\ Department of Electrical and Electronic Engineering, Joongbu University, Geumsan 312-702, Korea
}

Received October 9, 2012; Accepted November 6, 2012

\begin{abstract}
Epoxy/microsilica (65 phr)/nanosilica (0 5 phr) composites (EMNC) were prepared in order to develop a high-voltage insulation material, where phr means parts per hundred relative to the epoxy oligomer. Tensile and flexural tests of the composites were carried out, and the AC electrical breakdown strength was measured, after which all the data were estimated by Weibull statistical analysis. As the nanosilica content increased, the tensile strength increased, and the highest value was 117.7 MPa in the EMNC system with 3 phr nanosilica, which was ca. $10 \%$ higher than that of the system without nanosilica. The value then decreased after $3 \mathrm{phr}$. The flexural strength and AC electrical breakdown strength showed the same tendencies as the tensile strength. The highest value of the flexural strength was 184.6 MPa in the EMNC system with $3 \mathrm{phr}$ of nanosilica, which was ca. 15\% higher than that of the system without nanosilica. The strongest value of the AC electrical breakdown strength was $79.0 \mathrm{kV} / 0.5 \mathrm{~mm}$ in the EMNC system with 3 phr of nanosilica, which was ca. $34 \%$ higher than that of the system without nanosilica.
\end{abstract}

Keywords: Epoxy/microsilica/nanosilica composite, Tensile strength, Flexural strength, AC electrical breakdown strength, Weibull statistical analysis

\section{INTRODUCTION}

Various kinds of inorganic fillers such as zeolite [1], bentonite [2], silica $\left(\mathrm{SiO}_{2}\right)$ [3], alumina $\left(\mathrm{Al}_{2} \mathrm{O}_{3}\right)$ [4], mica [5], aluminum nitride (AlN) [6], titanium dioxide $\left(\mathrm{TiO}_{2}\right)$ [7], etc. have been incorporated into polymer matrices in order to reduce cost provide special properties, such as electrical insulation, modulus, hardness, thermal stability, and thickening [8,9]. However, differences in the elastic modulus or the thermal expansion coefficients between the inorganic fillers and the polymer matrices occur due to the weak interfacial characteristics, which have a negative effect on the electrical, mechanical, and thermal properties. Many have investigated the modification of the interfacial strength by

${ }^{\dagger}$ Author to whom all correspondence should be addressed: E-mail: jjpark@joongbu.ac.kr

Copyright @2012 KIEEME. All rights reserved. This is an open-access article distributed under the terms of the Creative Commons Attribution Non-Commercial
License (httr:///creativecommons.org/licenses/by-nc/3.0) which permits unrestricted noncommercial use, License (http://creativecommons.org/licensesslby-nc/3.0) which permits unrestricted
distribution, and reproduction in any medium, provided the original work is properly cited minimizing the filler size, which can be expressed in nano-scale units [10]. Epoxy resins are well-known materials for polymeric matrices for insulation systems in heavy electric equipment such as mold-type transformers, current transformers (CT), potential transformers (PT), metering outfits (MOF), and gas switching gears [11-13], because they have good mechanical and thermal properties and excellent electrical properties due to the crosslink reaction [14].

With microsilica was incorporated into an epoxy matrix, the dimensional stability, mechanical, and thermal properties of the neat epoxy system are improved during the manufacturing process or service life. A high level of microsilica content is loaded in an epoxy matrix in order to achieve the same low level of thermal expansion as that of copper or aluminum parts, which prevents exfoliation between the epoxy casting part and the metallic parts. This is because many electric apparatus are generally operated at $40 \sim 60^{\circ} \mathrm{C}$ and they are exposed to various heat cycles of environmental temperature [15]. In addition,microsilica can also enhance the electrical and thermal properties, hydrothermal aging, and UV resistance of an epoxy matrix during the manufac- 
turing process or service life.

In this paper, $2-\mu \mathrm{m}$ microsilica and $10-\mathrm{nm}$ nanosilica were incorporated into an epoxy matrix, and their tensile, flexural, and AC insulation breakdown strengths were measured. The microsilica content was fixed to $65 \mathrm{phr}$, and the nanosilica content was varied between $0 \sim 5 \mathrm{phr}$, where phr meants parts per one hundred relative to the epoxy base resin.

\section{EXPERIMENTS}

A commercial DGEBA (diglycidyl ether of bisphenol A) type epoxy resin whose trade name is YD 128 (Kukdo Chem. Co. Korea) was used. The epoxy equivalent weight (EEW) was 184 190 $\mathrm{g} / \mathrm{eq}$ and the viscosity was $11,500-13,500 \mathrm{cps}$ at $25^{\circ} \mathrm{C}$. The curing agent was Me-THPA (3- or 4-methyl-1,2,3,6-tetrahydrophthalic anhydride), whose grade name is $\mathrm{HN}-2200$ (Hitachi Chem. Co., Japan). It is widely used in the field of electrical insulation. The tertiary amine-type accelerator was BDMA (benzyl-dimethyl amine, Kukdo Chem. Co. Korea). CA0020microsilica with an average particle size of $2 \mu \mathrm{m}$ was purchased from Kosem Co. (Korea), and 10-nm nanosilica was purchased from Nanostructured \& Amorphous Materials.Inc. These were dried at $110^{\circ} \mathrm{C}$ for $24 \mathrm{hr}$ in a vacuum oven.

EMNCs were prepared by the following procedure: epoxy base resin (DGEBA, $30 \mathrm{~g}$ ) and nanosilica $(0,1,3$, 4, or $5 \mathrm{~g}$ ) were wellmixed in a bottle with a high-speed agitator at 5,000 rpm for 30 min. DGEBA (70 g) and microsilica (65 g) were well-mixed in another bottle with a high-speed agitator at 5,000 rpm for $30 \mathrm{~min}$, and then the first mixture was added to the second bottle at 5,000 rpm for $30 \mathrm{~min}$. THPA $(80 \mathrm{~g})$ and BDMA $(0.9 \mathrm{~g})$ were mixed for 5 min. Finally, the mixture was poured into a mold and degassed in a vacuum oven, and then cured at $120^{\circ} \mathrm{C}$ for $2 \mathrm{~h}$ and continually postcured at $150^{\circ} \mathrm{C}$ for $2 \mathrm{~h}$.

Dynamic mechanical analysis (DMA2980, TA Instrument Ltd.) was carried out in shear mode at a frequency of $1.0 \mathrm{~Hz}$ and heating rate of $10^{\circ} \mathrm{C} / \mathrm{min}$. The sample dimensions were $12.5 \times 7.0 \times 3.0$ $\mathrm{mm}$, and the air purge rate was $110 \mathrm{ml} / \mathrm{min}$.

Tensile and flexural tests were carried out using a universal testing machine (SHM-C-500, Shamhan Tech, Korea). Specimens for tensile tests were prepared under the recommendation of JIS B7502, and they were tested at a crosshead speed of $10 \mathrm{~mm} / \mathrm{min}$ at $23{ }^{\circ} \mathrm{C}$ and $50 \%$ relative humidity. Specimens for flexural tests were prepared by three-point bending method with the recommendation of JIS B7507 at a size of $70 \times 10 \times 4 \mathrm{~mm}$. The span length was $50 \mathrm{~mm}$ and the crosshead speed was $10 \mathrm{~mm} / \mathrm{min}$ at the same temperature and humidity as in the tensile test.

Sphere-plate electrodes were arranged to measure the AC insulation breakdown strength, as shown in Figure 1. The cast specimen was designed to have $0.25-\mathrm{mm}$ thickness at the thinnest point, and the electrodes were arranged at the point with the expectation that the insulation breakdown would take place in that point. However, edge breakdown took place in many cases, so the upper half of the sphere electrode was insulated with epoxy resin and PET film in order to prevent edge discharge and breakdown. The electrodes and specimen were dipped into insulating oil at $30^{\circ} \mathrm{C}$, and high voltage (HV) was applied until electrical breakdown with a rising speed of $2 \mathrm{kV} / \mathrm{s}$.

\section{RESULTS AND DISCUSSION}

Figure 2 shows DMA curves for EMNCs. The storage modulus of the EMNC-0phr at $40{ }^{\circ} \mathrm{C}$ (at the glass state) was 6,959 MPa , which increased, showing the highest value of 9,306 MPa in the EMNC system with 3 phr of nanosilica, which was ca. $30 \%$ higher

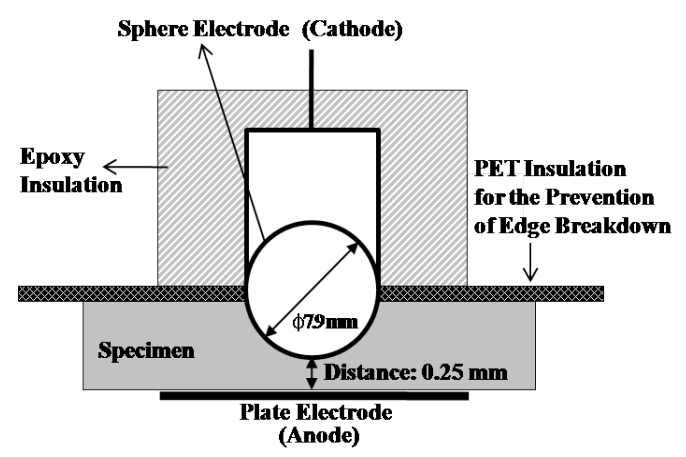

Fig. 1. Specimen preparation and electrodes arrangement for the prevention of edge breakdown [16].

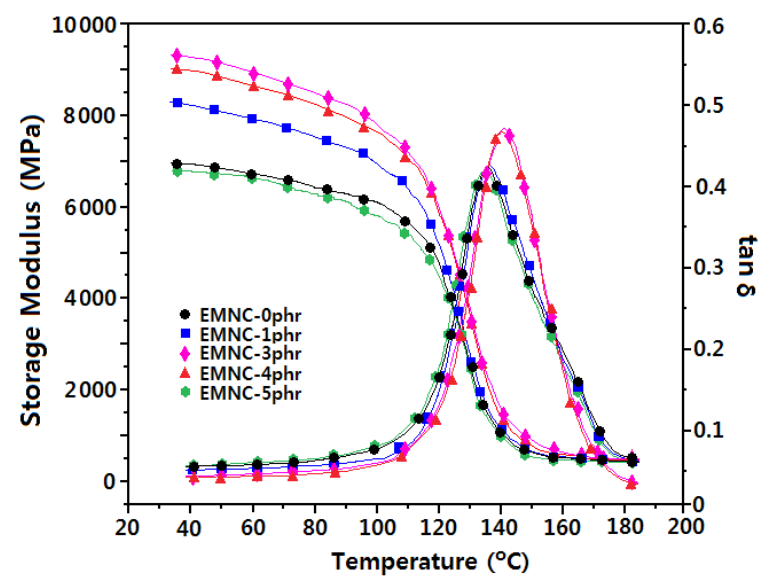

Fig. 2. DMA curves for EMNCs, which were cured at $120^{\circ} \mathrm{C}$ for $2 \mathrm{~h}$ and postcuring at $150^{\circ} \mathrm{C}$ for $2 \mathrm{~h}$.

than that of the system without nanosilica. The value then decreased after 3 phr. As the atmosphere temperature increased, the storage modulus $\left(G^{\prime}\right)$ decreased and abruptly dropped, and at the same time, the loss modulus (G") abruptly increased at the glass transition state, which was displayed in the form of $\tan \delta=$ G"/G'. The glass transition temperature ( $\mathrm{Tg}$ ) was estimated from the peak temperature of $\tan \delta$. The Tg value of the microsilica system without nanosilica was $136.2^{\circ} \mathrm{C}$, and that of the system was increased by $6.7^{\circ} \mathrm{C}$ after the addition of $3 \mathrm{phr}$ of nanosilica. However, the value decreased after 3 phr of nanosilica. When microsilica was added to the epoxy matrix, the microsilica could anchor the epoxy chains by the hydrogen bonding between silanol groups on the silica surface and hydroxyl groups in the epoxy matrix, so that the mobility of the epoxy chains became disturbed. The anchoring effect increased when the nanosilica was filled among the microsilica particles, so the Tg value increased. However, if the nanosilica content was too high, the nanoparticles aggregated, so that the filling effect among the microsilica particles decreased.

Figure 3 shows Weibull statistical analyses of the tensile strength for EMNCs, and parameters such as shape and scale parameters and B10 value were obtained from the Weibull plots. The sshape parameter could be obtained from the slope, representing the data distribution, and the scale parameter represented the tensile strength, at which the cumulative probability of expected failure is $63.2 \%$. The B10 value referred to the tensile strength at which $10 \%$ would fail ( $90 \%$ would survive) under a given stress. The statistical analysis showed that the scale param- 


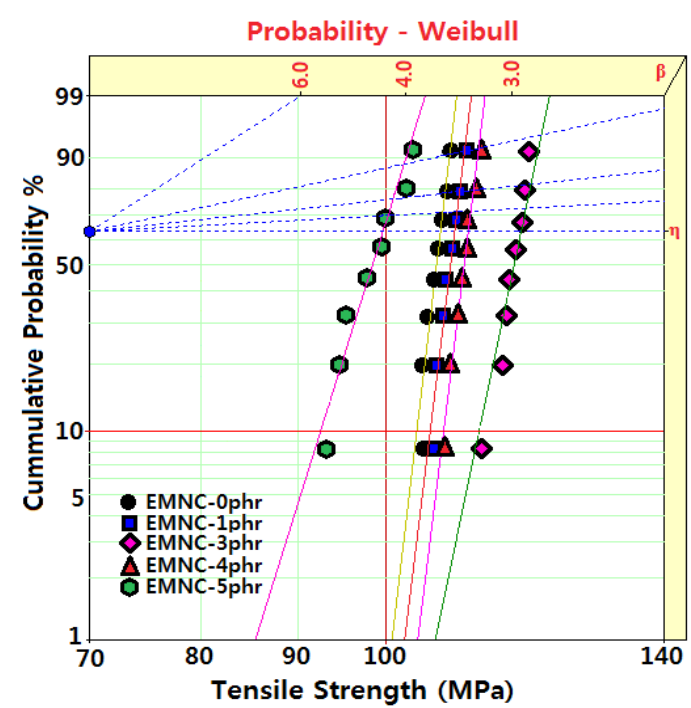

Fig. 3. Weibull statistical analyses of tensile strength for EMNCs, which were cured at $120^{\circ} \mathrm{C}$ for $2 \mathrm{~h}$ and postcuring at $150^{\circ} \mathrm{C}$ for $2 \mathrm{~h}$.

Table 1. Weibull parameters for tensile strength in EMNCs obtained from Fig. 2.

\begin{tabular}{cccc}
\hline $\begin{array}{c}\text { Nanosilica } \\
\text { content }\end{array}$ & Shape parameter & $\begin{array}{c}\text { Scale parameter } \\
(\mathrm{MPa})\end{array}$ & $\begin{array}{c}\text { B10 value } \\
(\mathrm{MPa})\end{array}$ \\
\hline $0 \mathrm{phr}$ & 29.9 & 106.9 & 103.8 \\
$1 \mathrm{phr}$ & 30.2 & 108.7 & 105.6 \\
$3 \mathrm{phr}$ & 19.3 & 117.7 & 111.9 \\
$4 \mathrm{phr}$ & 30.5 & 110.6 & 107.2 \\
$5 \mathrm{phr}$ & 11.4 & 99.7 & 92.4 \\
\hline
\end{tabular}

eter of the EMNC-0phr was 106.9 MPa with a shape parameter of 29.9, and as the nanosilica content increased, it increased,with the highest value being 117.7 MPa in the EMNC system with $3 \mathrm{phr}$ of nanosilica.This value was ca. $10 \%$ higher than that of the system without nanosilica. Then the value decreased after 3 phr. As explained in Fig. 2, microsilica could anchor the epoxy chains by hydrogen bonding between silanol groups on the silica surface and hydroxyl groups in the epoxy matrix, so that the mobility of the epoxy chains became disturbed, and so the tensile strength increased. However, when the nanosilica content was too high, the nanoparticles aggregated, so that the epoxy matrix could not wet the inner surface among the aggregated nanosilicas. Therefore, when the external stress was applied to the aggregated nanosilica, cracks were easily initiated from the inner surface and the tensile strength decreased after the addition of 3 phr of nanosilica. The Weibull parameters obtained from Fig. 3 are listed in Table 1.

With the increment of nanosilica content, the same tendency was observed in the flexural strength, as shown in Fig. 4. The Weibull parameters obtained from Fig. 4 are listed in Table 2. The scale parameter of the EMNC-0 phr was 160.7 MPa with a shape parameter of 15.7, and as the nanosilica content increased, The flexural strength increased with the highest value being184.6 MPa in the EMNC system with $3 \mathrm{phr}$ of nanosilica. This value was ca. $15 \%$ higher than that of the system without nanosilica, and the value decreased after $3 \mathrm{phr}$.

Figure 5 shows Weibull statistical analyses of the AC insulation breakdown strength for EMNCs, and the parameters are listed in Table 3. As the nanosilica content increased, the microsilica and nanosilica could anchor the epoxy chains, as explained in Fig. 2. The scale parameter of the EMNC-0phr was $59.1 \mathrm{kV} / 0.25 \mathrm{~mm}$,

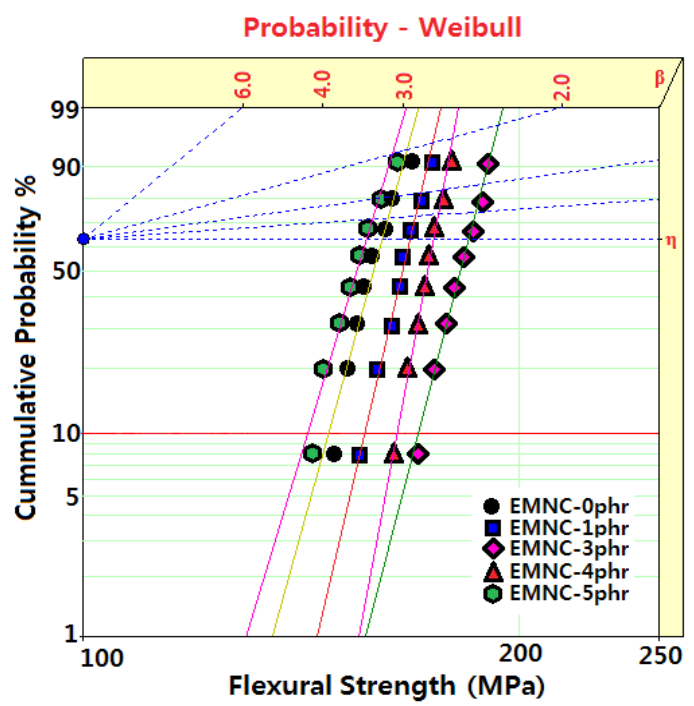

Fig. 4. Weibull statistical analyses of flexural strength for EMNCs, which were cured at $120^{\circ} \mathrm{C}$ for $2 \mathrm{~h}$ and postcuring at $150^{\circ} \mathrm{C}$ for $2 \mathrm{~h}$.

Table 2. Weibull parameters for flexural strength in EMNCs obtained from Fig. 3.

\begin{tabular}{cccc}
\hline $\begin{array}{c}\text { Nanosilica } \\
\text { content }\end{array}$ & Shape parameter & $\begin{array}{c}\text { Scale parameter } \\
\text { (MPa) }\end{array}$ & $\begin{array}{c}\text { B10 value } \\
(\mathrm{MPa})\end{array}$ \\
\hline \hline $0 \mathrm{phr}$ & 15.7 & 160.7 & 147.6 \\
$1 \mathrm{phr}$ & 16.6 & 168.1 & 156.2 \\
$3 \mathrm{phr}$ & 14.6 & 184.6 & 170.1 \\
$4 \mathrm{phr}$ & 18.2 & 174.4 & 163.9 \\
$5 \mathrm{phr}$ & 14.4 & 156.8 & 142.5 \\
\hline
\end{tabular}

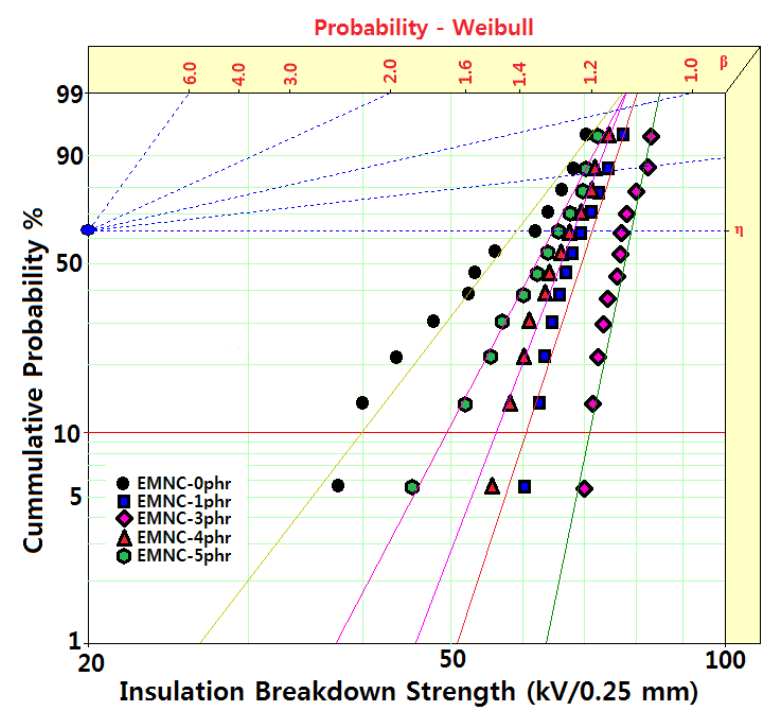

Fig. 5. Weibull statistical analyses of AC insulation breakdown strength for EMNCs, which were cured at $120^{\circ} \mathrm{C}$ for $2 \mathrm{~h}$ and postcuring at $150^{\circ} \mathrm{C}$ for $2 \mathrm{~h}$.

and that of the EMNC-3 phr was $79.0 \mathrm{kV} / 0.25 \mathrm{~mm}$, an improvement of $34 \%$. This can be explained by the mechanism for the deterioration of polymeric insulators [17]. Charges injected from the sphere electrode to the EMNC insulation and then inversely extracted from the EMNC insulation to the sphere electrode cyclically, and then an electrical tree was initiated from the sphere 
Table 3. Weibull parameters for AC insulation breakdown strength for EMNCs obtained from Fig. 4.

\begin{tabular}{cccc}
\hline $\begin{array}{c}\text { Nanosilica } \\
\text { content }\end{array}$ & Shape parameter & $\begin{array}{c}\text { Scale parameter } \\
(\mathrm{kV} / 0.25 \mathrm{~mm})\end{array}$ & $\begin{array}{c}\text { B10 value } \\
(\mathrm{kV} / 0.25 \mathrm{~mm})\end{array}$ \\
\hline \hline phr & 18.7 & 59.1 & 39.9 \\
$1 \mathrm{phr}$ & 21.2 & 71.6 & 60.6 \\
$3 \mathrm{phr}$ & 22.9 & 79.0 & 71.2 \\
$4 \mathrm{phr}$ & 21.0 & 68.2 & 56.2 \\
$5 \mathrm{phr}$ & 19.4 & 64.9 & 49.6 \\
\hline
\end{tabular}

electrode. And Then, as charges were injected to the EMNC from the carbonized conductive tree tip and inversely extracted, the tree grew rapidly in the propagation process. Finally, the penetration breakdown took place. Thus, the tree growth should be retarded or blocked by adding inorganic fillers into a polymeric insulation in order to obtain good AC insulation breakdown strength.

In the EMNC-0phr system, large microsilica particles retarded the tree growth, but electrons could flow relatively easily around the interface between sphere-like microsilica and the epoxy matrix, and they resulted in new electric field concentration at the opposite side of the microsilica interface. If nanosilica was packed into the microsilica particles, the barrier effect increased. These results mean that the microsilica and nanosilica acted as good barriers. When microsilica and nanosilica were added to epoxy matrix, the particles could anchor the epoxy chains by the hydrogen bonding between silanol groups on the silica surface and hydroxyl groups in the epoxy matrix, so that the interfacial characteristics improved. Therefore, the barrier effect of the silica particles on the tree growth rate was favorable.

\section{CONCLUSIONS}

Epoxy/microsilica/nanosilica composites (EMNCs) were prepared in order to develop a high-voltage insulation material, and tensile and flexural tests were carried out, and the AC electrical breakdown strength was measured. The microsilica content was fixed at 65 phr and the nanosilica content was varied between $0 \sim 5$ phr. All the data were estimated by Weibull statistical analysis. As the nanosilica content increased, the tensile strength increased, and the highest value was given in the EMNC system with 3 phr of nanosilica. This value decreased after 3 phr. The flexural strength and AC electrical breakdown strength showed the same tendencies as the tensile strength. This was due to the good interfacial characteristics between the silica particles and epoxy matrix. The microsilica could anchor the epoxy chains by the hydrogen bonding between silanol groups on the silica surface and hydroxyl groups in the epoxy matrix, so that the mobility of the epoxy chains became disturbed. The anchoring effect increased when the nanosilica was filled among the microsilica particles.

\section{ACKNOWLEDGMENT}

This work was supported by Joongbu University (2012).

\section{REFERENCES}

[1] J. Y. Lee, M. J. Shim and S. W. Kim, Polym. Eng. Sci., 39, 1993 (1999) [DOI: http://dx.doi.org/10.1002/pen.11592].

[2] J. Y. Lee and H. K. Lee, Mater. Chem. Phys., 85, 410 (2004) [DOI: http://dx.doi.org/10.1016/j.matchemphys.2004.01.032].

[3] P. O. Henk, T. W. Kortsen and T. Kvarts, High Perform. Polym., 11,281 (1999) [DOI: http://dx.doi.org/10.1088/09540083/11/3/304].

[4] M. Ehsani, Z. Farhadinejad, S. Moemen-bellah, S. M. Bagher alavi, M. M. S. Shrazi and H. Borsi, $26^{\text {th }}$ Internal Power System Conference, Tehran, Iran, 11-E-CAM-2359 (2011).

[5] P. Bajaj, N. K. Jha and A. Kumar, J. Appl. Polym. Sci., 56, 1339 (1995) [DOI: http://dx.doi.org/10.1002/app.1995.070561015].

[6] Y. Xu, D. D. L. Chung and C. Mroz, Composites: Part A, 32, 1749 (2001) [DOI: http://dx.doi.org/10.1016/S1359835X(01)00023-9].

[7] A. A. Wazzan, H. A. Al-Turaif and A. F. Abdelkader, PolymerPlastics Technology and Engineering, 45, 1155 (2006) [DOI: http://dx.doi.org/10.1080/03602550600887285].

[8] T. Seçkin, A. Gültek, M. G. Içduygu and Y. Önal, J. Appl. Polym. Sci., 84, 164 (2002) [DOI: http://dx.doi.org/10.1002/app.10289].

[9] F. Lin, G. S. Bhatia and J. D. Ford, J. Appl. Polym. Sci., 49, 1901 (1993) [DOI: http://dx.doi.org/10.1002/app.1993.070491105].

[10] T. Imai, F. Sawa, T. Ozaki, T. Shimizu, R. Kido, M. Kozako and T. Tanaka, Intern. Sympos. Electr. Insulating Materials, Kitakyushu, Japan, pp. 239-242, 2005.

[11] R. Sarathi, R. K. Sahu and P. Rajeshkumar, Mater. Sci. Eng.: A, 445, 567 (2007) [DOI: http://dx.doi.org/10.1016/ j.msea.2006.09.077].

[12] N. Hayakawa, H. Maeda, S. Chigusa and H. Okubo, Cryogenics, 40, 167 (2000) [DOI: http://dx.doi.org/10.1016/s00112275(00)00024-2].

[13] G. Iyer, R. S. Gorur, R. Richert, A. Krivda and L. E. Schmidt, IEEE Trans. Dielectr. Electr. Insul., 18, 659 (2011) [DOI: http://dx.doi. org/10.1109/TDEI.2011.5931050].

[14] L. Matějka, J. Lövy, S. Pokorný, K. Bouchal and K. Dušek, J. Polym. Sci.: Part A, 21, 2873 (1983) [DOI: http://dx.doi. org/10.1002/pol.1983. 170211003].

[15] J. J. Park, K. G. Yoon and J. Y. Lee, Trans. Electr. Electron. Mater. 12, 98 (2011) [DOI: http://dx.doi.org/10.4313/ TEEM.2011.12.3.98].

[16] J. J. Park, Y. B. Park and J. Y. Lee, Trans. Electr. Electron. Mater. 12, 93 (2011) [DOI: http://dx.doi.org/10.4313/ TEEM.2011.12.3.93].

[17] L. A. Dissado, IEEE Transactions on Dielectrics and Electrical Insulation, 9, 483 (2002) [DOI: http://dx.doi.org/10.1109/ TDEI.2002.1024425]. 